\title{
MODELLING THE THERMAL DECOMPOSITION OF AUTOMOTIVE SHREDDER RESIDUE
}

\author{
Juan A. Conesa ${ }^{a}$, Lorena Rey, Ignacio Aracil \\ Department of Chemical Engineering. University of Alicante \\ P.O. Box 99, 03080 Alicante (Spain). \\ Phone: +(34) 965903867 Fax: +(34) 965903826 \\ Author email address: ja.conesa@ua.es
}




\section{ABSTRACT}

The pyrolysis and combustion of automotive shredder residue (ASR) were studied by dynamic thermogravimetry and derivative thermogravimetry (TG-DTG) at heating rates of 5, 15 and $30 \mathrm{~K} \mathrm{~min}^{-1}$ at atmospheric pressure. For the simulation of pyrolysis and combustion processes two different kinetic models are proposed. One of them is based on the distribution of activation energies (DAEM), with three pools of reactants (three pseudocomponents) because of the complexity of the samples studied. The other model assumes a simple first-order decomposition of the three different fractions. The experimental thermogravimetric data of pyrolysis (oxygen absence) and combustion (at two different oxygen concentrations) processes were simultaneously fitted to determine a single set of kinetic parameters able to describe both processes at the different heating rates. The comparison of the models permits to discuss the importance to consider a distribution of activation energies. The experimental results and kinetic parameters may provide useful data for the design of thermal decomposition processing system using ASR as feedstock.

\section{Keywords}

Pyrolysis, Combustion, Kinetic parameters, thermogravimetry, ASR 


\section{Introduction}

Automobile shredder residue (ASR) is a heterogeneous material defined as the fraction that remains after depolluting, dismantling, shredding of the hulk and recovery of metals from end-of-life vehicles (ELVs). The main characteristic of this residue is its heterogeneous composition which has been demonstrated by a great number of studies [1, 2]. ASR is a complex mixture of plastics (19-35\%), rubber (20\%), textile (10-40\%), wood (2-5\%), metals (8\%), oils (5\%) and others unidentifiable materials (10\%) [3]. Polymers are the most valuable components of ASR: polyvinyl chloride (PVC), polyethylene (PE) or polypropylene (PP) [4]. Higher heating value, 11.8-18.7 $\mathrm{MJ} \mathrm{kg}^{-1}$ [3] is also an important characteristic of ASR, making it suitable for energy recovery as a RDF. ASR is the sum of two material fractions: light and heavy fluffs, which are obtained at different stages of the shredding process. This residual fraction accounts for $10-25 \%$ of the initial ELV's mass and used to be mostly sent to landfill. [1-4].

In September 2000, the Directive 2000/53/EC on end-of-life vehicles was adopted. The main objective of this Directive was waste prevention. Moreover, the Directive stated the accomplishment of a minimum rate of reuse and recovery of $95 \%$ and a minimum rate of re-use and recycling of $85 \%$ both by average weight per vehicle and year to be reached by 2015 .

This means that in order to reach those rates, many studies have been focused on energy recovery from ASR. Some studies have concluded that the option of energy recovery combined with recycling is the most suitable alternative for ASR [5].

Guo et al. [5] studied the gas release behavior of ASR using a TG-MS apparatus both in nitrogen and mixtures $\mathrm{N}_{2} / \mathrm{O}_{2}$; the authors conclude that the final weight remaining after ASR decomposition decreased from $43.4 \%$ to $10.1 \%$ with increasing oxygen concentrations. Furthermore, the production rates of hydrogen, methane and carbon dioxide also varied with different $\mathrm{N}_{2} / \mathrm{O}_{2}$ volume ratios, logically presenting the maximum emission of hydrogen and methane when the atmosphere $\mathrm{N}_{2}$, as there is not availability of oxygen to react with these compounds [6]. Also a work dealing with the thermal decomposition of these kind of wastes was done by Rausa and Pollesel [7], where the authors evaluate the chemicals generated during the decomposition.

Kinetic data are indispensable for designing any sort of device in which a thermal decomposition takes places. Furthermore, kinetics is the starting point to propose mechanisms for the thermal decomposition [6].

During the thermal decomposition of materials in the presence of oxygen, three different behaviors can be distinguished [8, 9]: pyrolysis + combustion of the residue formed (i.e., during the combustion process there is a first step of pyrolysis, followed by the reaction of oxygen with the residue of pyrolysis), oxidative pyrolysis (in this case, the combustion takes place in parallel to pyrolysis; combustion is faster and takes place at lower temperatures; oxygen reacts with the solid that is being decomposed before reaching the flame formation), and combustion delayed respect to the pyrolysis (the presence of oxygen produces partial oxygenation of solid material, causing the apparent delay in the decomposition of the solid). Wastes decomposition studies are 
usually based on kinetic models considering several independent parallel reactions, associated with the main pseudo-components.

Although commercial thermogravimetric systems have a high precision, the sample temperature is not directly measured or controlled. In the presence of oxygen, given the high exothermicity of the combustion reactions, a thermal runaway may occur with the temperature inside the sample becoming considerably higher than that foreseen by the assigned program and the sample being oxidized at high reaction rate. Unfortunately, numerous thermogravimetric measurements reported in literature about wastes combustion show the occurrence of thermal runaway, with the consequent formulation of erroneous reaction mechanisms. A significant number of studies are available where, in addition to the determination of the weight loss characteristics, the examination of the data has led to mechanisms of different complexity with kinetic parameters, in particular the activation energies, dependent on the conversion level and/or the heating rate. In other cases, only a single heating rate is considered. These models although based on experimental data apparently not impugned by heat and mass transfer effects, are not truly valid over widely variable conditions. Indeed, only kinetic models capable of explaining the shift in the thermogravimetric curves with the heating rate, without changing the kinetic parameters, can be considered potentially correct [10].

The aim of this study was to develop a kinetic model for the thermal decomposition of ASR both in the absence and in the presence of oxygen, by simultaneous fitting of thermogravimetric curves obtained at different heating rates. In the study, a distributed activation energy-model (DAEM) with three pools of reactants (three pseudocomponents) was used, and it was compared to a simple first-order decomposition of the three different fractions.

\section{Experimental}

\subsection{ASR Characterization}

The material employed in this study was ASR collected from a cement kiln factory owned by the CEMEX group sited in Alicante (Spain). The ASR has a split appearance due to the diverse materials of its composition, which means it is a highly heterogeneous material. Prior to the characterization, ASR was crushed with a laboratory blender and using immersion in liquid-nitrogen in order to homogenize it. The material was grinded using immersion in liquid-nitrogen until a sieve size range of 1-2 mm. Figure 1 shows a picture of the material before and after being crushed.

[Figure 1]

Table 1 presents the ultimate analysis as well as the calorific values of the sample. The elemental analysis was carried out in a Perkin-Elmer 2400 CHNS analyzer, the moisture content was determined by weight loss at $105^{\circ} \mathrm{C}$ for $12 \mathrm{~h}$ and the ash residue was obtained by calcination at $850^{\circ} \mathrm{C}$. The net calorific value was determined by a calorimetric bomb AC-350 Leco Instruments. 
Table 2 shows the semi-quantitative analysis of the remaining elements, performed by X-ray fluorescence with an automatic sequential spectrometer (model TW 1480, Philips Magix Pro, Philips Co., Ltd.).

\section{[Table 1]}

[Table 2]

\subsection{Thermobalance}

A Mettler Toledo thermobalance model TGA/SDTA851e/LF/1600 with TG-DTA was used to carry out the thermal decomposition study of the ASR as part of the characterization of their properties. This apparatus has a horizontal furnace and a parallel-guide balance. The position of the sample has no influence in the measurement, and flow gas perturbation and thermal buoyancy are minimized. The sample temperature was measured with a sensor directly attached to the sample holder.

Three different atmospheres were studied: inert atmosphere of $\mathrm{N}_{2}$ (pyrolysis) and oxidative atmospheres $\mathrm{N}_{2}: \mathrm{O}_{2}=9: 1$ (10\% of oxygen, poor oxygen condition) and $\mathrm{N}_{2}: \mathrm{O}_{2}=4: 1$ (20\% oxygen, normal condition). Runs were carried out with a flow rate of $100 \mathrm{~mL} \mathrm{~min}^{-1}$.

Dynamic experiments were carried out at different heating rates for each atmosphere (5, 15 and $\left.30 \mathrm{~K} \mathrm{~min}^{-1}\right)$, from room temperature up to $1173 \mathrm{~K}$. Sample mass in TG runs was maintained between 8 and $10 \mathrm{mg}$ in order to minimize the risks of a thermal runaway, especially in the oxidative atmosphere runs.

\section{Kinetic models and optimization method}

As mentioned before, for the decomposition of the ASR two different models were tested, in all the atmospheres studied. The most simple is a model considering the first order parallel decompositions of different fractions (components). In literature, Donaj et al. [11] presented also a model considering three different decomposition peaks for ASR pyrolysis process and assumed independent first order decomposition for three fractions.

During the thermal decomposition of ASR, as will be shown later, three main decomposition steps are observed so three different fractions will be considered, in such a way that:

$$
\begin{aligned}
& \mathrm{C}_{\mathrm{s}_{10}} \text { Solid }_{1} \stackrel{1}{\longrightarrow}\left(\mathrm{c}_{\mathrm{s}_{10}}-\mathrm{v}_{1 \infty}\right) \text { Char }_{1}+\mathrm{v}_{1 \infty} \text { Volatiles }_{1} \\
& c_{s_{20}} \text { Solid }_{2} \stackrel{2}{\longrightarrow}\left(c_{s_{20}}-v_{2 \infty}\right) \text { Char }_{2}+v_{2 \infty} \text { Volatiles }_{2} \\
& c_{s_{30}} \text { Solid }_{3} \stackrel{3}{\longrightarrow}\left(c_{s_{30}}-v_{3 \infty}\right) \text { Char }_{3}+v_{3 \infty} \text { Volatiles }_{3}
\end{aligned}
$$


In the previous reactions, Solid $_{1}$, Solid $_{2}$ and Solid $_{3}$ refer to different fractions or components of the original material, "Volatiles," are the gases and condensable volatiles evolved in the corresponding reactions ( $\mathrm{i}=1$ to 3), and "Char," is the char formed in the decomposition of each Solid $(i=1$ to 3 ). On the other hand, the small letters represent the yield coefficients ( $\mathrm{kg}$ of species/kg initial sample) representative of each reaction and consequently, they are considered not to be changing with time and with the extension of the reaction. Moreover, each fraction has a yield coefficient that represents the maximum mass fractions obtainable by each reaction; in this sense, $\mathrm{v}_{\mathrm{i} \infty}$ is the yield coefficient for the Volatiles $_{\mathrm{i}}$ and $\left(\mathrm{C}_{\mathrm{si} 0}-\mathrm{v}_{\mathrm{i} \infty}\right)$ is the yield coefficient for the solid char, being $v_{i}$ the mass fractions of the volatiles. The different initial mass fractions of the components ( $\mathrm{c}_{\mathrm{si}}=$ weight of fraction $\mathrm{i}$ in the initial sample/total weight of sample) are related so the following must be fulfilled:

$$
\sum_{i=1}^{3} c_{s_{i 0}}=1
$$

Considering a first order kinetic decomposition, the kinetic equations for the pyrolysis runs can be expressed as followed:

$-\frac{d w_{s_{i}}}{d t}=k_{i} w_{s_{i}} \quad$ or $\quad \frac{d v_{i}}{d t}=k_{i}\left(v_{i \infty}-v_{i}\right)$

with the kinetic constants following the Arrhenius equation:

$\mathrm{k}_{\mathrm{i}}=\mathrm{k}_{\mathrm{i} 0} \exp \left(-\frac{\mathrm{E}_{\mathrm{i}}}{\mathrm{RT}}\right) \quad \mathrm{i}=1$ to 3

In the equations, $v_{i}$ and $v_{i \infty}$ represent the volatiles evolved from the decomposition of each fraction, and the maximum yield of volatiles that can be obtained, respectively. For the calculation of the total mass remaining a weighted sum is used: 
For the optimization of 3 TG curves (approx. 300 experimental points), 8 parameters were obtained ( $3 \mathrm{x} \mathrm{E}_{\mathrm{i}}$, 3x $\mathrm{k}_{\mathrm{i} 0}$ and $2 \mathrm{x} \mathrm{c}_{\mathrm{si}}$ ) when using this model. The calculated values were obtained by integration of the differential equations presented in the kinetic model, by the explicit Runge-Kutta method, considering and testing that the intervals of time are small enough so the errors introduced are negligible. The optimization method of the function Solver in a Microsoft Excel spreadsheet was used to minimize the differences between experimental and calculated mass loss derivatives. The objective function (OF) to minimize was the sum of the square differences between experimental and calculated mass loss derivative values:

$$
O . F .=\sum_{j} \sum_{k}\left[\left(\frac{d w_{s}}{d t}\right)_{\exp _{k j}}-\left(\frac{d w_{s}}{d t}\right)_{\text {calc }_{k j}}\right]^{2}
$$

where ' $k$ ' represents the experimental data at time 't' in the experiment with a heating rate ' $j$ '. The value of $\left(\frac{d w_{s}}{d t}\right)_{\exp _{k j}}$ or $\left(\frac{d w_{s}}{d t}\right)_{\text {cal }_{k j}}$ represents the derivative mass loss fraction in the experimental and calculated data, respectively.

Furthermore, a DAEM was selected and used in the present work for analyzing the decomposition of ASR trying to explain some deficiencies found in the first-order decomposition model. Distributed activation energy models (DAEMs) have been used for biomass pyrolysis kinetics since 1985, when Avni et al. [12] applied a DAEM for the formation of volatiles from lignin. DAEM has been used mainly to explain the thermal decomposition of different biomass feedstock with very good results [13-15].

DAEM assumes different parallel first-order reactions with a Gaussian activation energy distribution. In the model, the sample is composed by the sum of $\mathrm{M}$ pseudocomponents, similar to the first-order modelling presented before. In DAEM, the parameter M is usually between 2 and 4. A pseudocomponent represents the totality of the species decomposing that can be described by the same reaction kinetic parameters. In a complex material as ASR, obviously the number of reacting species is much higher than M. The reactivity differences are described by different activation energy values. On a molecular level, each species in pseudocomponent ' $\mathrm{j}$ ' is assumed to undergo first-order decomposition. The corresponding rate constant $(\mathrm{k})$ is supposed to depend on the temperature by an Arrhenius relationship:

$$
\mathrm{k}(\mathrm{T})=\mathrm{k}_{\mathrm{j} 0} \exp \left(-\frac{\mathrm{E}}{\mathrm{RT}}\right)
$$


In this sense, first-order kinetics is a particular case of a DAEM where the width of the Gaussian distribution is nil. In this sense, the Gaussian distribution becomes a Dirac delta function. Or, in other words, DAEM is a generalization of first-order kinetics to an undefined number of components.

If $\alpha_{\mathrm{j}}$ is defined as the normalized weight loss:

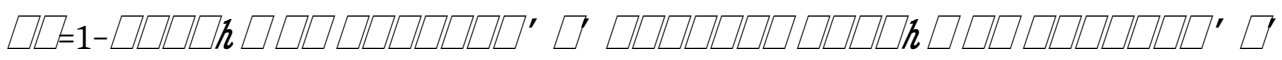

Let $\alpha_{j}(t, E)$ be the solution of the corresponding first-order kinetic equation at a given $\mathrm{E}$ and $\mathrm{T}(\mathrm{t})$ with conditions $\alpha_{\mathrm{j}}(0, \mathrm{E})=0$ and $\alpha_{\mathrm{j}}(\infty, \mathrm{E})=1$ :

$D_{j}(E)$ will refer to the density function of the species differing by $E$ within a given pseudocomponent. $D_{j}(E)$ is approximated by a Gaussian distribution with a mean $\mathrm{E}_{0, \mathrm{j}}$ and width parameter $\sigma_{\mathrm{j}}$ :

$\square \square \square=1 \square \square 2 \square \exp \quad-12 \square-\square, \square \square \square / 2$

The overall reacted fraction of the jth pseudocomponent, $\alpha_{j}(t)$ is obtained by integration:

\section{$\square \square \square=0 \infty \square \square \square \square \square \square \square, \square \square \square$}

During the calculation, 100 fractions of each pseudocomponent were considered, each one of them having different activation energy, comprising all the values according to the Gaussian distribution. A partial value of $\alpha_{j}(t, E)$ at the time "t" of the run is calculated, and finally the weighted sum of all the fractions represented by eq. (11) gives the total normalized weight loss of the pseudocomponent. The normalized sample mass, $\mathrm{w}_{\mathrm{s}}$, and its derivative are the linear combinations of $\alpha_{\mathrm{j}}(\mathrm{t})$ and $\mathrm{d} \alpha_{\mathrm{j}} / \mathrm{dt}$, respectively:

$-\square \square \square \square \square=\square=1 \square \square \square \square \square \square \square \square \square \quad$ and $\quad \square \square=1-\square=1 \square \square \square \square \square \square$ 
where a factor $\mathrm{c}_{\mathrm{s} j 0}$ is introduced that equals the amount of volatiles formed by a unit mass of pseudocomponent. Note that, if the DAEM is reduced to the simple combination of first-order kinetics, the values of $\mathrm{c}_{\mathrm{sjo}}$ would correspond to the different initial fractions of the components.

The unknown model parameters were evaluated from series of experiments by minimizing the sum $S_{N}$ of the differences between the observed data and their counterparts calculated from the given model:

\section{$\square \square=\square=1 \square \square \square \square \square \square \square \square \square \square \square-\square \square \square \square \square \square \square \square \square \square \square 2$}

where $N$ is the number of curves evaluated simultaneously, a subscript $k$ indicates the different experiments, $t_{i}$ denotes the time values in which the discrete experimental values were taken, $N$ is the number of $t_{i}$ points in a given experiment. Note that equations (6) and (13) denote both the differences between calculated and experimental derivative curves of the runs.

For the decomposition of ASR, a good result has been obtained by using M=3 (three pseudocomponents) both in pyrolytic and in oxidant atmospheres. The software used for optimization has been Matlab®, and the programs were developed by the authors. Matlab ${ }^{\circledR}$ function 'fmincon' is used for optimization of the parameters, that allows to using linear and nonlinear constraints (such as the sum of coefficients $\mathrm{c}_{\mathrm{s} j \mathrm{0}}$ is unity), as well as bounds for the values of the optimized variables. The parameters to be optimized, considering three pseudocomponents, will be: three values of $k_{j 0}$, three values of $E_{0, j}$, three values of $\sigma_{j}$ and two values of $c_{s j 0}$, because the sum of all three $c_{\mathrm{sj} 0}$ must be unity (11 parameters in total). Different authors $[16,14]$ pointed out a strong compensation effect between the parameters of the DAEM, in such a way that different pairs of kinetic parameters provide an equally good fit to experimental data. Varhegyi et al. [14] suggest to delimitate the values of the pre-exponential factors to $10^{11}-10^{16} \mathrm{~s}^{-1}$ in order to be consistent with the transition-state theory. In the present work, a lower and upper bound for $k_{j 0}$ was assumed, in the range $10^{10}-10^{20} \mathrm{~s}^{-1}$.

The points represented in the Figures, which have been those used for the kinetic analysis, have been selected according to techniques recommended by Caballero et al. [17] so that:

- The derivative of the points is calculated accurately and correctly, i.e., using a time interval enough to assure that the magnitude of the errors in the weight measure is negligible.

- The points are equally spaced on a representation derivative of weight versus temperature.

- The fitting is simultaneous, with no variation of the kinetic constants, for at least three different heating rates. 


\section{Results and discussion}

\subsection{First order kinetic model}

Figures 2 to 4 present the thermal decomposition of ASR in pyrolytic and oxidant atmospheres, at the three heating rates used. Note that in the presence of air (combustion runs) highly exothermic processes are present, leading to a distortion of the usual behavior in thermal decompositions, where an increase of the decomposition temperature as the heating rate increases is expected $[18,19]$. Logically, this effect is more pronounced at $20 \%$ oxygen $\left(\mathrm{N}_{2}: \mathrm{O}_{2}=4: 1\right)$ than at $10 \%\left(\mathrm{~N}_{2}: \mathrm{O}_{2}=9: 1\right)$. The Figures show the experimental points together with the fitting obtained by using the first order model. Note that the fitting is not good, especially in the combustion runs, but this will be improved later, when DAEM is used to fit the data. Figure 5 shows the derivative weight loss curves (DTG) of the ASR in the three different atmospheres at the lower heating rate, in order to compare the decompositions. It is important to note that both the pyrolysis and combustion DTG curves indicate three different processes (three different minima in Figure 5). In the presence of oxygen it seems that the first and third processes are promoted, whereas the importance of the second process diminishes, i.e., the components decomposing in the second reaction in nitrogen are affected by the presence of oxygen, and decompose at lower temperatures, while the formed chars burn off resulting in a larger mass loss step in the region of the 3rd reaction.

[Figures 2-5]

The decomposition in oxygen atmosphere (combustion) is oxidative pyrolysis type (as described before), as can be seen in Figures 3-4, i.e., the combustion takes place in parallel to pyrolysis but it is faster, in such a way that the decomposition is not of the type pyrolysis + combustion of the residue formed that is found in other materials $[9,8]$.

Table 3 presents the kinetic constants optimized for the decomposition. For the decomposition in the presence of oxygen, the model used is the same used in pyrolytic conditions, and the same values of apparent activation energy obtained under a nitrogen atmosphere have been considered, but the pre-exponential factor could change due to the presence of the oxygen. This type of model satisfactorily fitted the decomposition of other materials [20-22] and is based in the fact that the primary thermal decomposition of the material could be considered unchanged in the presence of oxygen, which obviously would react with the primary products accelerating the process. This is considered in the model by the variation of the pre-exponential factors between the pyrolysis and the oxidation. It is clear that best fits would be obtained if all parameters are allowed to vary for each heating rate, but they would be less representative of the overall process. Note that, in order to obtain a single set of parameters, all the heating rates in each series were described by the same set of parameters.

\section{[Table 3]}

With all these considerations, fit quality shown in Figures 2 to 4 is obtained. It is important to mention that, obviously, the fitting is better if reaction orders are allowed to vary, but the use of reaction orders different 
from unity has been previously related to models that probably will not work at conditions different from these where were obtained [23].

Note that also the values of $\mathrm{c}_{\mathrm{si} 0}$ are maintained for the different heating rates, although it would be more legitimate to let these values vary, due to the heterogeneity of the sample considered. This is done for the sake of simplicity. The values of $\mathrm{c}_{\text {si } 0}$ obtained, represent approximately 18, 57 and $25 \%$ of the initial sample mass; these values would rather correspond to different fractions in the initial ASR sample. Looking to the nature and composition of a typical ASR, first fraction could correspond to a mixture of plastics; the second one would be related to the rubber and textiles, and the third one to other components.

\subsection{Distribution of Activation Energies Kinetic Model}

As it has been commented, if the order is allowed to vary a better fit would be obtained. Nevertheless, instead to vary the reaction order, it has been demonstrated that a distribution of activation energies in first-order decomposition of different pseudocomponents is more correct [24-26, 14, 13]. In this sense, the same experimental data on the decomposition of ASR has been modelled by using a DAEM, and the results obtained are presented in Figures 6 to 8.

In the DAEM for the combustion runs, an assumption equivalent to that mentioned before for the first-order model has been done, in such a way that the pre-exponential factors have been allowed to vary, but not the activation energies. Furthermore, as mentioned before, a lower and upper bound for pre-exponential factors was assumed, in the range $10^{10}-10^{20} \mathrm{~s}^{-1}$.

In a first approximation, the mean values of the a Gaussian distributions of the activation energies, $E_{0, j}$, were maintained to the values found in the previous first-order simplified model, in order to check the importance to take into consideration the distribution of activation energies. Unhappily, the results were not satisfactory and the $\mathrm{E}_{0, \mathrm{j}}$ values were allowed to vary respect to the simplified model.

Additionally, the presence of oxygen would produce a higher reactivity of the different species, what can be taken into account if the width parameter $\sigma_{\mathrm{j}}$ is allowed to vary; presumably it will be broader in the presence of oxygen. As can be seen in Figures 6-8 the fitting is very much satisfactory now. Table 4 shows the detailed values of the parameters used in the models.

[Figures 4-6]

[Table 4]

As can be seen in Figures 6-8 the fitting is much better than using the first-order model, although the behaviour of the combustion runs in the presence of $20 \%$ oxygen is very difficult to justify if the model does not include heat effects. The values of the contribution of each pseudocomponent to the total weight $\left(\mathrm{c}_{\mathrm{si} 0}\right)$ obtained are ca. 21, 50 and $29 \%$, indicating a very good similarity with the previous simplified model. 


\subsection{Comparison of the first-order and DAEM models}

Figure 9 shows the distribution of activation energies optimized for the pyrolysis and combustion with $10 \%$ oxygen. These are the Gaussian normal distributions obtained in the optimization and their parameters are shown in Table 4. Note that two distributions (those corresponding to the second ant the third process) are completely overlapped in the pyrolysis, and there is a small difference in the combustion. The values of $E_{0, j}$ and $\sigma_{j}$ reflected in Table 4 indicate this behavior. For comparison, a straight line has been included in Figure 9, corresponding to the activation energies obtained in the first-order simplified model. Note that in the simple model, the activation energy of the first process is very much similar.

[Figure 9]

Respect to the values of the width parameter $\sigma_{j}$, there is a very important increment of the $\sigma_{2}$ value in the presence of oxygen, indicating that oxygen is able to react with fractions that are not affected in the case of pyrolytic process. Nevertheless, the value of this with parameter for the first pseudo-component in the combustion process is somewhat lower (i.e. DAEM less broad) for pseudo component 1.

Table 4 also shows the ratio between the values of the pre exponential factors of the constants obtained in combustion and in pyrolysis. From the values obtained it seems that the first and third fractions accelerate their decomposition in the presence of oxygen (as was observed before when discussing the form of the DTG curve), whereas this is not true for the first fraction.

\section{Conclusions}

Kinetic modeling of the pyrolysis and combustion of ASR has been discussed. Both processes can be satisfactorily fitted using DAEM with three pseudocomponents. One set of parameters in each case can explain all the experiments at the different heating rates used $\left(5,15\right.$ and $\left.30 \mathrm{~K} \mathrm{~min}^{-1}\right)$. First order model is able to explain a limited amount of experimental data, whereas the model including a distribution of activation energies explains more results, including the decomposition in the presence of oxygen.

Furthermore, combustion runs have been fitted with another set of kinetic constants by maintaining the activation energies found in pyrolysis.

\section{Acknowledgements}

Support for this work was provided by the CTQ2013-41006-R project from the Ministry of Economy and Competitiveness (Spain) and the PROMETEOII/2014/007 project from the Valencian Community Government (Spain). 


\section{Literature cited}

1. Gonzalez-Fernandez O, Hidalgo M, Margui E, Carvalho ML, Queralt I. Heavy metals' content of automotive shredder residues (ASR): Evaluation of environmental risk. Environ Pollut. 2008;153(2):476-82. doi:10.1016/j.envpol.2007.08.002. 2. Santini A, Morselli L, Passarini F, Vassura I, Di Carlo S, Bonino F. End-of-Life Vehicles management: Italian material and energy recovery efficiency. Waste Manage (Oxford). 2011;31(3):489-94. doi:10.1016/j.wasman.2010.09.015.

3. Morselli L, Santini A, Passarini F, Vassura I. Automotive shredder residue (ASR) characterization for a valuable management. Waste Manage (Oxford). 2010;30(11):2228-34. doi:10.1016/j.wasman.2010.05.017.

4. Reddy MS, Kurose K, Okuda T, Nishijima W, Okada M. Selective recovery of PVC-free polymers from ASR polymers by ozonation and froth flotation. Resources, Conservation and Recycling. 2008;52(6):941-6. doi:10.1016/j.resconrec.2008.02.003.

5. Guo $Q$, Zhang X, Li C, Liu X, Li J. TG-MS study of the thermo-oxidative behavior of plastic automobile shredder residues. J Hazard Mater. 2012;209-210:443-8. doi:10.1016/j.jhazmat.2012.01.051.

6. Conesa JA, Font R, Fullana A, Martín-Gullón I, Aracil I, Gálvez A et al. Comparison between emissions from the pyrolysis and combustion of different wastes. Journal of Analytical and Applied Pyrolysis. 2009;84(1):95-102.

7. Rausa R, Pollesel P. Pyrolysis of automotive shredder residue (ASR) Influence of temperature on the distribution of products. Journal of Analytical and Applied Pyrolysis. 1997;40-41:383-401.

8. Font R, Fullana A, Conesa J. Kinetic models for the pyrolysis and combustion of two types of sewage sludge. Journal of Analytical and Applied Pyrolysis. 2005;74(1-2):429-38.

9. Conesa JA, Font R, Fullana A, Caballero JA. Kinetic model for the combustion of tyre wastes. Fuel. 1998;77(13):146975.

10. Conesa JA, Domene A. Biomasses pyrolysis and combustion kinetics through $\mathrm{n}$-th order parallel reactions. Thermochimica Acta. 2011;523(1-2):176-81.

11. Donaj P, Yang W, Blasiak W, Forsgren C, editors. Kinetic study of decomposition of ASR residues after pyrolysis in inert and oxidative atmosphere. Joint Conference: International Thermal Treatment Technologies (IT3) and Hazardous Waste Combustors (HWC); 2009.

12. Avni E, Coughlin RW, Solomon PR, King HH. Mathematical modelling of lignin pyrolysis. Fuel. 1985;64(11):1495-501. doi:10.1016/0016-2361(85)90362-x.

13. Várhegyi G, Szabó $P$, Jakab E, Till F. Least squares criteria for the kinetic evaluation of thermoanalytical experiments. Examples from a char reactivity study. Journal of Analytical and Applied Pyrolysis. 2001;57(2):203-22.

14. Várhegyi G, Bobály B, Jakab E, Chen H. Thermogravimetric study of biomass pyrolysis kinetics. A distributed activation energy model with prediction tests. Energy Fuels. 2011;25(1):24-32.

15. Conesa JA, Urueña A, Díez D. Corn stover thermal decomposition in pyrolytic and oxidant atmosphere. Journal of Analytical and Applied Pyrolysis. 2014;106:132-7. doi:10.1016/j.jaap.2014.01.010.

16. de Jong W, Di Nola G, Venneker BCH, Spliethoff H, Wójtowicz MA. TG-FTIR pyrolysis of coal and secondary biomass fuels: Determination of pyrolysis kinetic parameters for main species and NOx precursors. Fuel. 2007;86(15):2367-76. doi:10.1016/j.fuel.2007.01.032.

17. Caballero JA, Conesa JA. Mathematical considerations for nonisothermal kinetics in thermal decomposition. Journal of Analytical and Applied Pyrolysis. 2005;73(1):85-100.

18. Gómez-Rico MF, Martín-Gullón I, Fullana A, Conesa JA, Font R. Pyrolysis and combustion kinetics and emissions of waste lube oils. Journal of Analytical and Applied Pyrolysis. 2003;68-69:527-46.

19. Font R, Conesa JA, Molto J, Munoz M. Kinetics of pyrolysis and combustion of pine needles and cones. Journal of Analytical and Applied Pyrolysis. 2009;85(1-2):276-86.

20. Aracil I, Font R, Conesa JA, Fullana A. TG-MS analysis of the thermo-oxidative decomposition of polychloroprene. Journal of Analytical and Applied Pyrolysis. 2007;79(1-2 SPEC. ISS.):327-36.

21. Conesa JA, Moltá J, Font R, Egea S. Polyvinyl chloride and halogen-free electric wires thermal decomposition. Industrial and Engineering Chemistry Research. 2010;49(22):11841-7.

22. Conesa JA, Rey L. Thermogravimetric and kinetic analysis of the decomposition of solid recovered fuel from municipal solid waste. J Therm Anal Calorim. 2015;120(2):1233. doi:10.1007/s10973-015-4396-4.

23. Caballero JA, Conesa JA. New approach to thermal analysis kinetics by considering several first order reactions. Thermochimica Acta. 2011;525(1-2):40-9.

24. Miura K. A new and simple method to estimate $f(E)$ and $\mathrm{kO}(\mathrm{E})$ in the distributed activation energy model from three sets of experimental data. Energy \& Fuels. 1995;9(2):302-7.

25. Miura K, Maki T. A simple method for estimating $f(E)$ and $k 0(E)$ in the distributed activation energy model. Energy Fuels. 1998;12(5):864-9.

26. Suuberg EM, Peters WA, Howard JB. Product composition and kinetics of lignite pyrolysis. Industrial \& Engineering Chemistry Process Design and Development. 1978;17(1):37-46. 



\section{LIST OF FIGURES AND TABLES}

Figure 1. ASR before and after being crushed.

Figure 2. Thermal decomposition of ASR in inert atmosphere (pyrolysis) at three different heating rates. Experimental and calculated points using simplified parallel first-order kinetics.

Figure 3. Thermal decomposition of ASR in $10 \%$ oxygen at three different heating rates. Experimental and calculated points using simplified parallel first-order kinetics.

Figure 4. Thermal decomposition of ASR in $20 \%$ oxygen at three different heating rates. Experimental and calculated points using simplified parallel first-order kinetics.

Figure 5. Comparison among the thermal decomposition of ASR in inert atmosphere (pyrolysis) and in the presence of 10 and $20 \%$ oxygen at $5 \mathrm{~K} \mathrm{~min}^{-1}$.

Figure 6. Thermal decomposition of ASR in inert atmosphere (pyrolysis) at three different heating rates. Experimental and calculated points using DAEM.

Figure 7. Thermal decomposition of ASR in $10 \%$ oxygen at three different heating rates. Experimental and calculated points using DAEM.

Figure 8. Thermal decomposition of ASR in $20 \%$ oxygen at three different heating rates. Experimental and calculated points using DAEM.

Figure 9. Distribution of activation energies optimized for the pyrolysis and combustion with $10 \%$ oxygen. Activation energies of the simplified first-order model are included for comparison.

Table 1. Ultimate analysis of the ASR sample used in the study (ultimate analysis over air dried sample).

Table 2. Fluorescence analysis of the ASR.

Table 3. Optimized kinetic constants for ASR decomposition using simplified parallel first-order kinetics.

Table 4. Optimized kinetic constants for ASR decomposition using DAEM. 


\section{Figures}
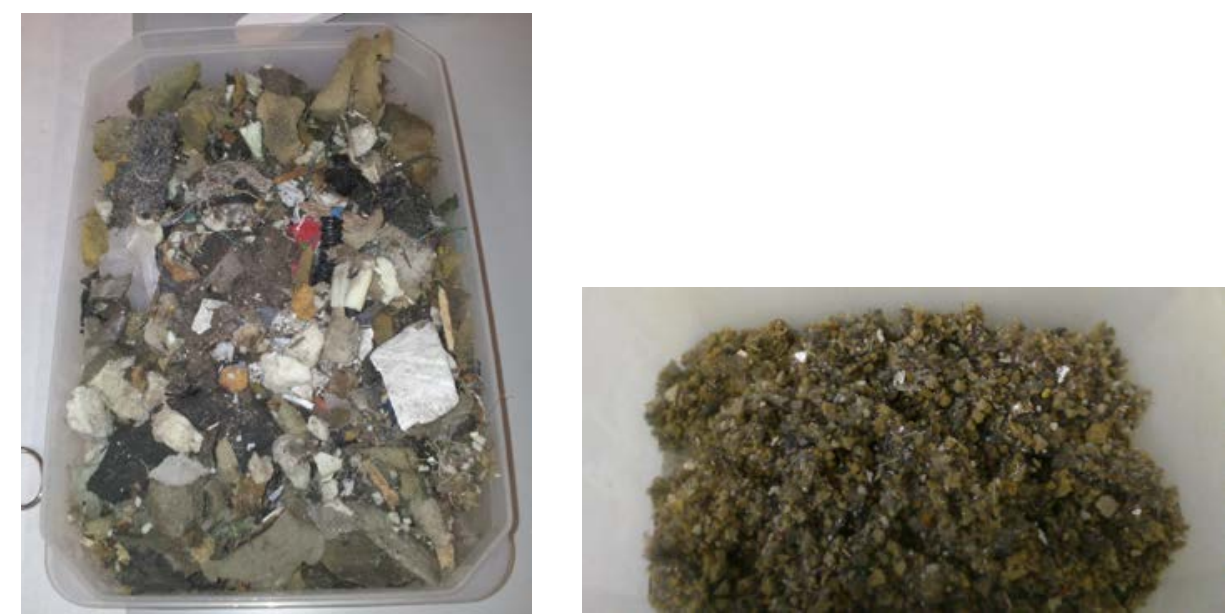

Figure 1. ASR before and after being crushed.

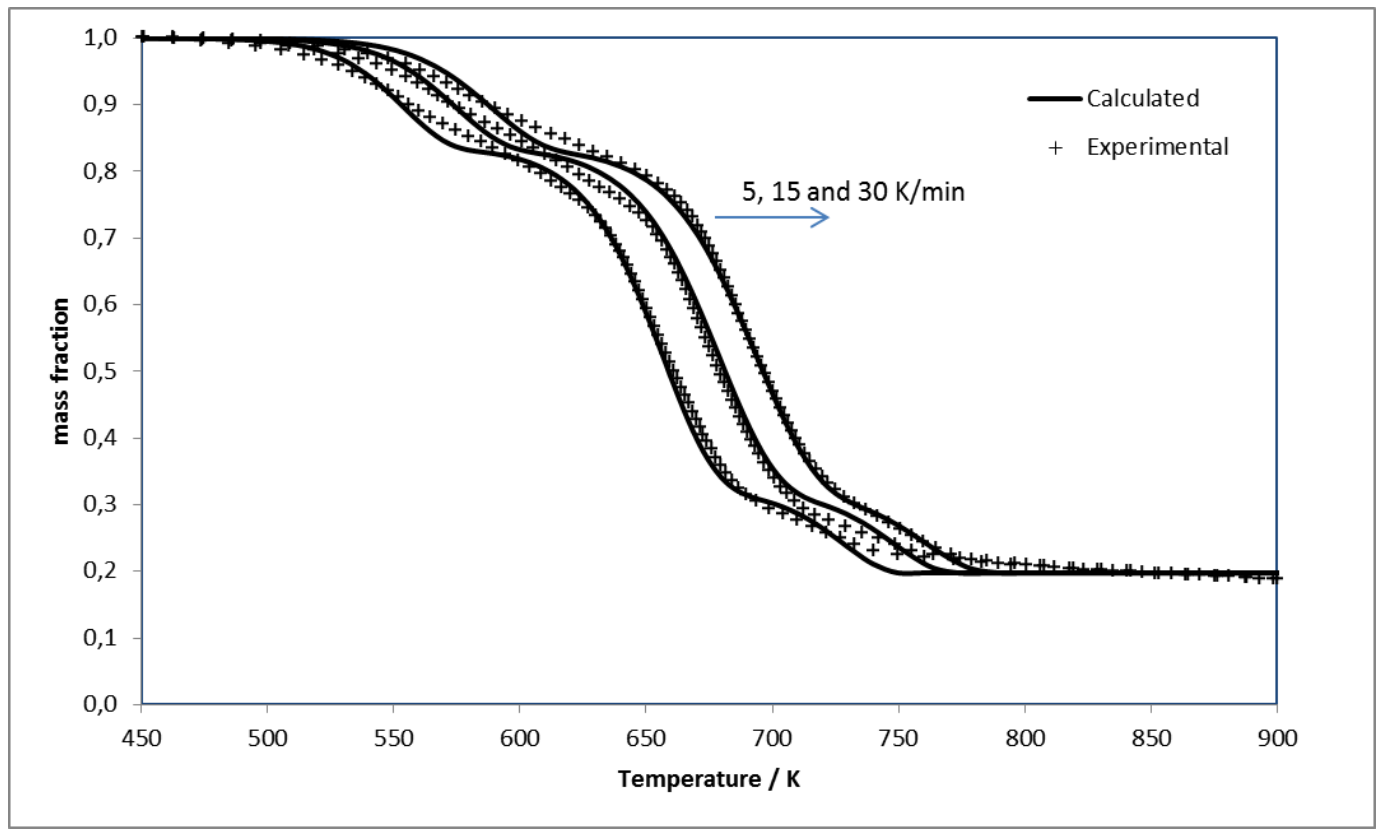

Figure 2. Thermal decomposition of ASR in inert atmosphere (pyrolysis) at three different heating rates. Experimental and calculated points using simplified parallel first-order kinetics. 


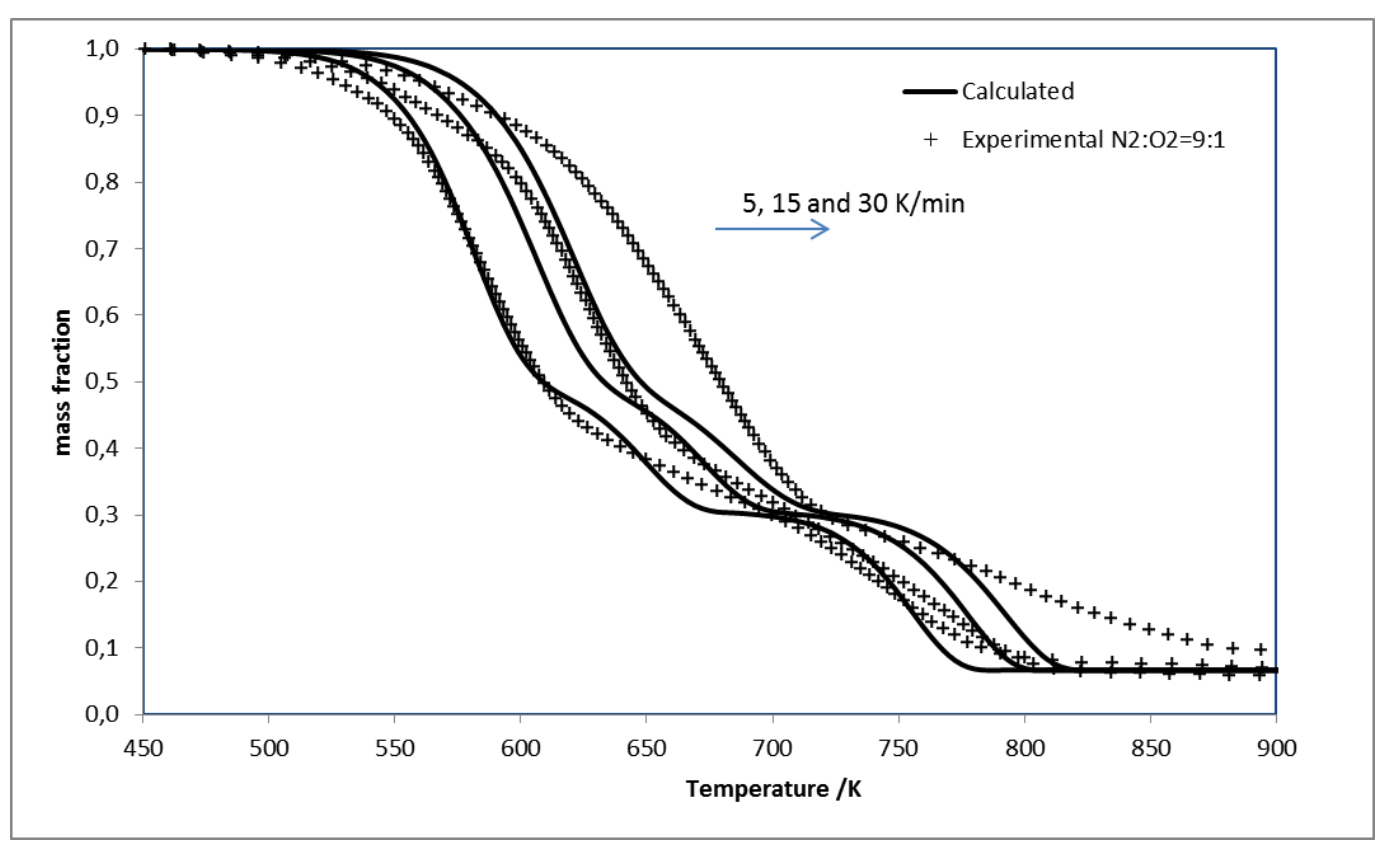

Figure 3. Thermal decomposition of ASR in $10 \%$ oxygen at three different heating rates. Experimental and calculated points using simplified parallel first-order kinetics.

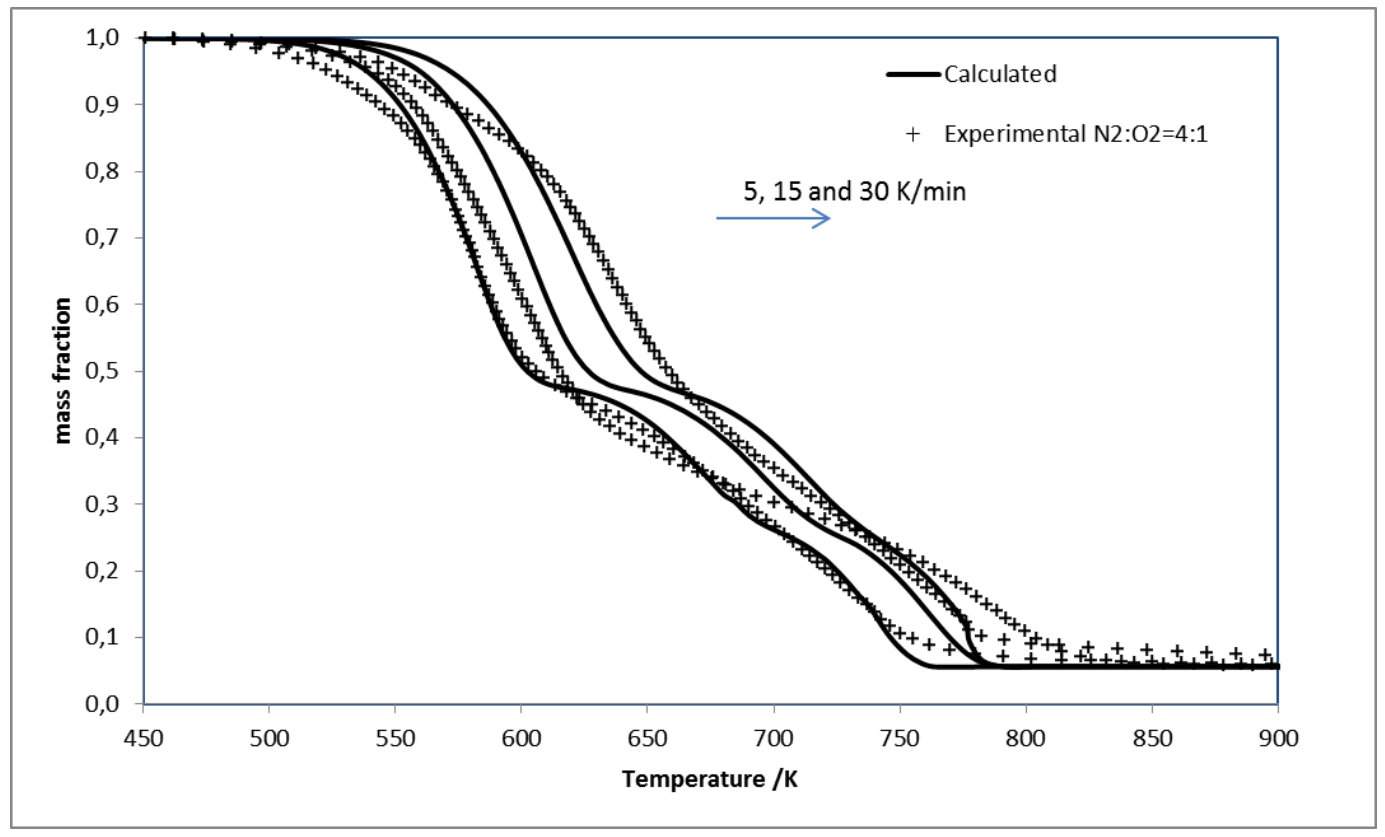

Figure 4. Thermal decomposition of ASR in $20 \%$ oxygen at three different heating rates. Experimental and calculated points using simplified parallel first-order kinetics. 


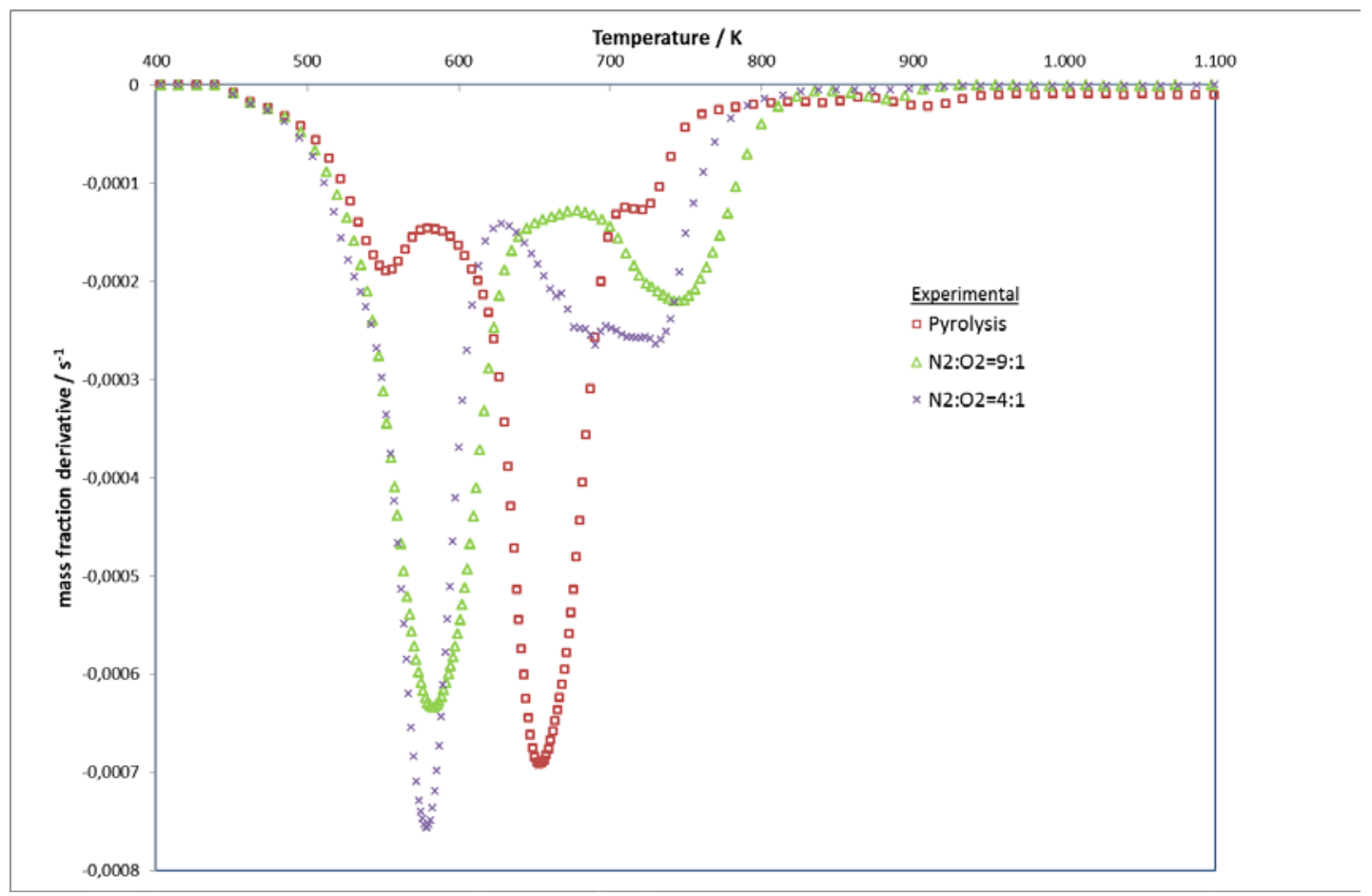

Figure 5. Comparison among the thermal decomposition of ASR in inert atmosphere (pyrolysis) and in the presence of 10 and $20 \%$ oxygen at $5 \mathrm{~K} \mathrm{~min}^{-1}$. 


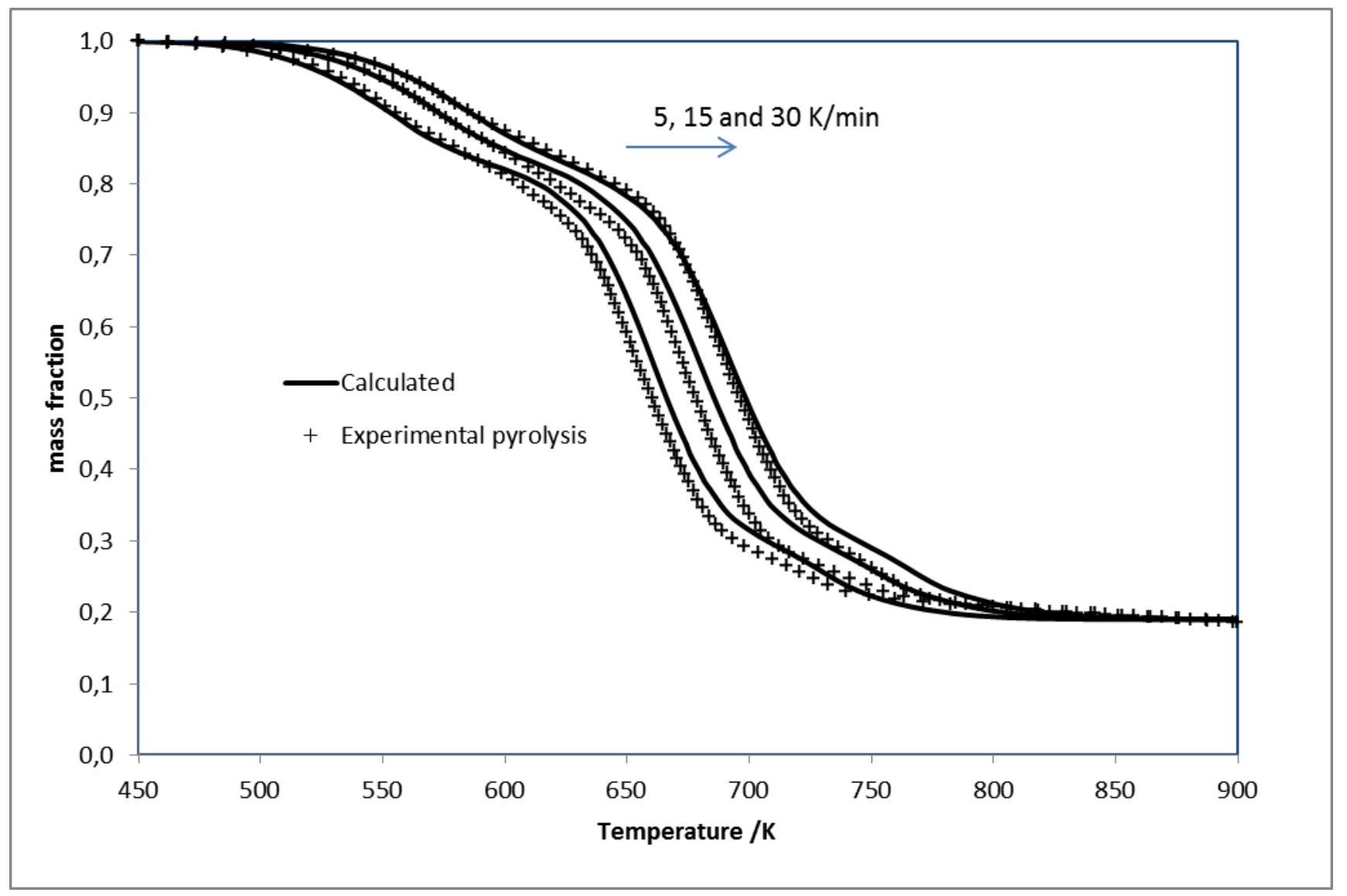

Figure 6. Thermal decomposition of ASR in inert atmosphere (pyrolysis) at three different heating rates. Experimental and calculated points using DAEM. 


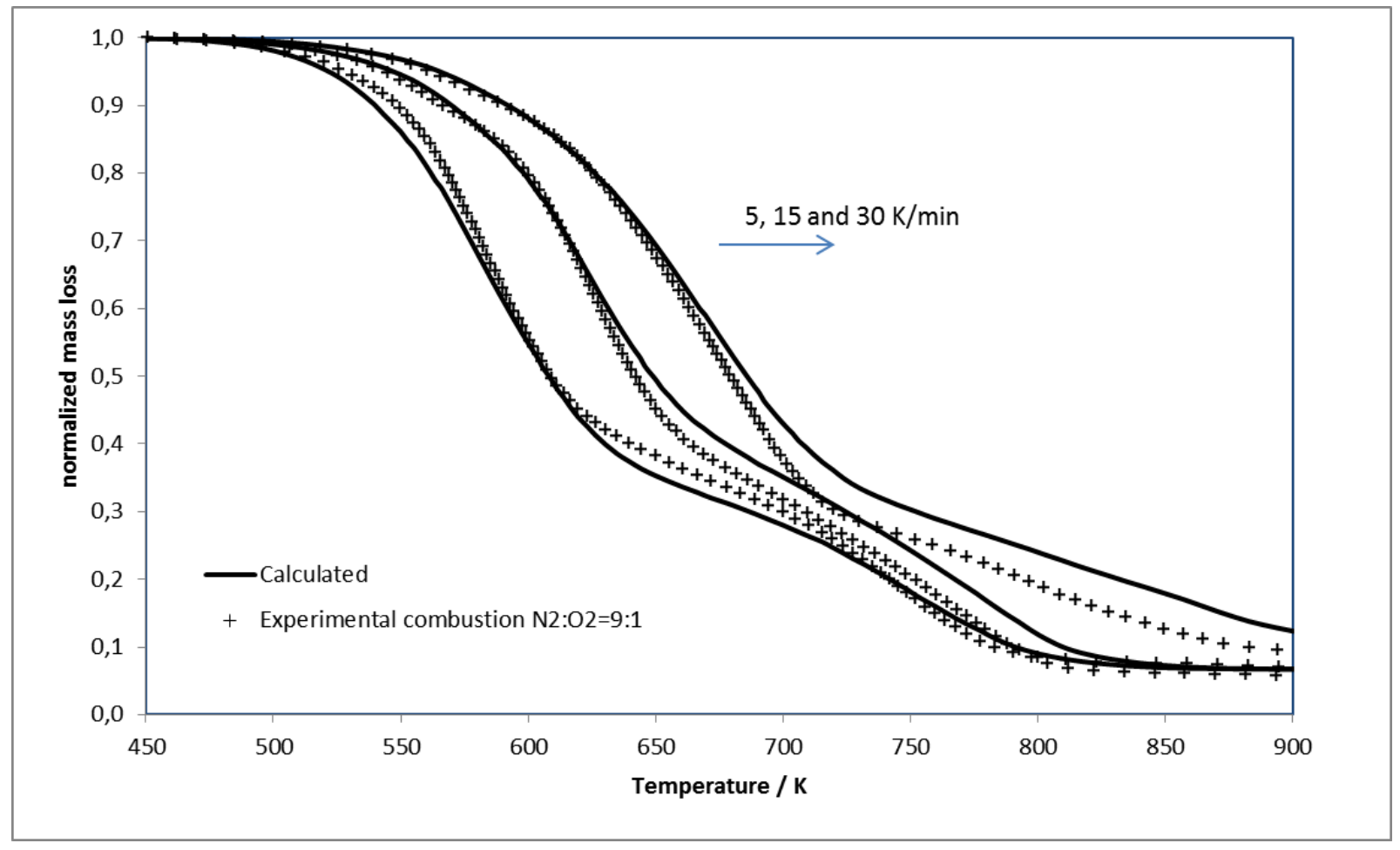

Figure 7. Thermal decomposition of ASR in $10 \%$ oxygen at three different heating rates. Experimental and calculated points using DAEM.

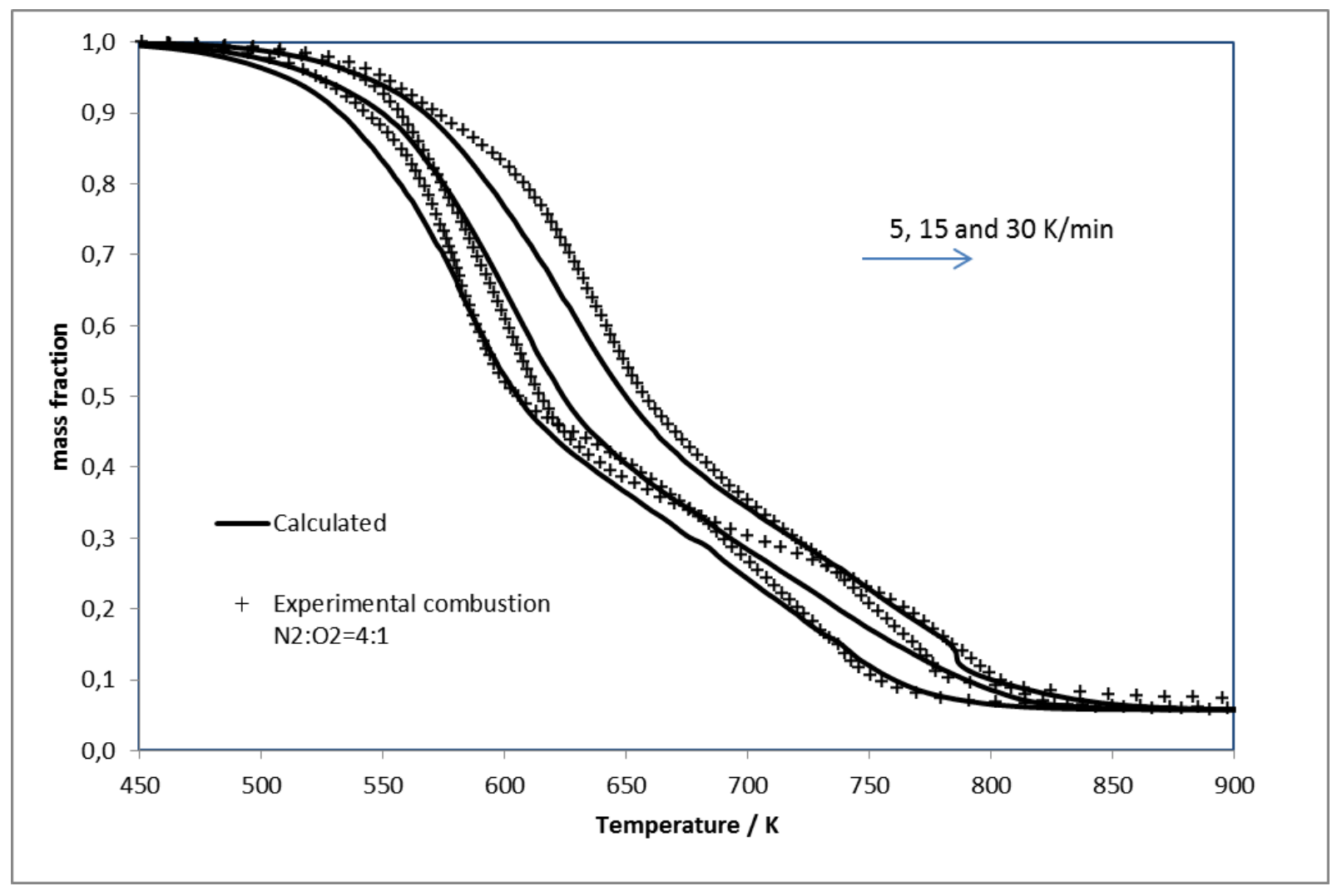

Figure 8. Thermal decomposition of ASR in $20 \%$ oxygen at three different heating rates. Experimental and calculated points using DAEM. 


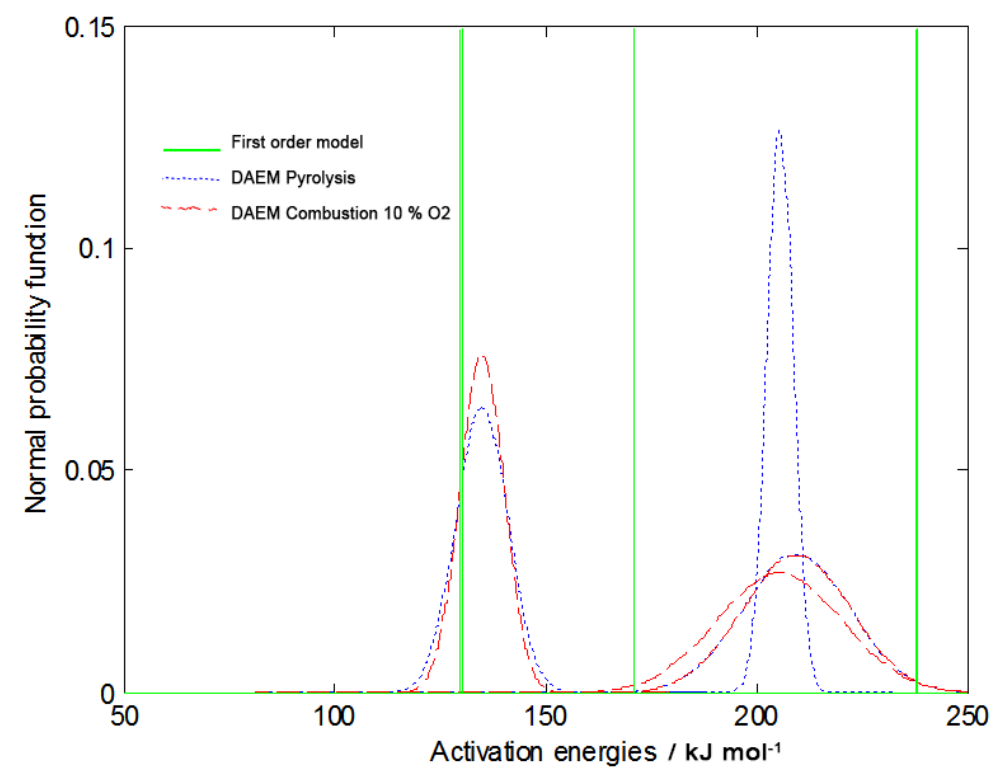

Figure 9. Distribution of activation energies optimized for the pyrolysis and combustion with $10 \%$ oxygen. Activation energies of the simplified first-order model are included for comparison. 
Table 1. Ultimate analysis of the ASR sample used in the study (ultimate analysis over air dried sample).

\begin{tabular}{ll}
\hline & ASR \\
\hline Moisture / wt. \% & 1.95 \\
NCV / kJ kg & 18750 \\
\hline Ash / wt. \% & 22.1 \\
\hline Volatile / wt. \% & 57.9 \\
\hline Fixed carbon/ wt. \% & 18.0 \\
\hline Element & wt. \% \\
\hline N & 3.73 \\
C & 56.61 \\
H & 7.22 \\
S & 0.01 \\
\hline O (by difference) & 13.36 \\
\hline
\end{tabular}

Table 2. Fluorescence analysis of the ASR.

\begin{tabular}{ll}
\hline & ASR \\
\hline Metal & $\mathrm{mg} \mathrm{kg}^{-1}$ \\
\hline Cu & 8100 \\
Zn & 11800 \\
Al & 7500 \\
Fe & 57500 \\
Mn & 1050 \\
Ni & 520 \\
Pb & 11400 \\
Ca & 55800 \\
Si & 18100 \\
\hline
\end{tabular}


Table 3. Optimized kinetic constants for ASR decomposition using simplified parallel first-order kinetics.

\begin{tabular}{|l|c|c|c|}
\hline & Pyrolysis & $\begin{array}{c}\text { Combustion } \\
\mathbf{N}_{2}: \mathbf{O}_{2}=\mathbf{9 : 1}\end{array}$ & $\begin{array}{c}\text { Combustion } \\
\mathbf{N}_{\mathbf{2}}: \mathbf{O}_{2}=\mathbf{4 : 1}\end{array}$ \\
\hline $\mathrm{k}_{01}, \mathrm{~s}^{-1}$ & $1,0210^{10}$ & $2,2510^{9}$ & $2,5910^{9}$ \\
\hline $\mathrm{E}_{01}, \mathrm{~kJ} \mathrm{~mol}^{-1}$ & \multicolumn{3}{|c|}{130,5} \\
\hline $\mathrm{k}_{02}, \mathrm{~s}^{-1}$ & $1,7710^{11}$ & $2,7310^{11}$ & $9,6810^{10}$ \\
\hline $\mathrm{E}_{02}, \mathrm{~kJ} \mathrm{~mol}^{-1}$ & \multicolumn{3}{|c|}{171,3} \\
\hline $\mathrm{k}_{03}, \mathrm{~s}^{-1}$ & $7,3310^{14}$ & $1,4910^{14}$ & $3,6010^{14}$ \\
\hline $\mathrm{E}_{03}, \mathrm{~kJ} \mathrm{~mol}^{-1}$ & \multicolumn{3}{|c|}{$0,185,7$} \\
\hline $\mathrm{c}_{\mathrm{s} 10}$ & \multicolumn{3}{|c|}{0,567} \\
\hline $\mathrm{C}_{\mathrm{s} 20}$ & \multicolumn{3}{|c|}{0,246} \\
\hline $\mathrm{C}_{\mathrm{s} 30}$ (calculated) & \multicolumn{3}{|c|}{} \\
\hline
\end{tabular}


Table 4. Optimized kinetic constants for ASR decomposition using DAEM.

\begin{tabular}{|c|c|c|c|}
\hline & Pyrolysis & $\begin{array}{l}\text { Combustion } \\
\mathrm{N}_{2}: \mathrm{O}_{2}=9: 1\end{array}$ & $\begin{array}{l}\text { Combustion } \\
\mathrm{N}_{2}: \mathrm{O}_{2}=4: 1\end{array}$ \\
\hline $\mathrm{k}_{01}, \mathrm{~s}^{-1}$ & $1,9410^{10}$ & $4,3110^{9}$ & $6,5610^{9}$ \\
\hline $\mathrm{E}_{0,1}, \mathrm{~kJ} \mathrm{~mol}^{-1}$ & \multicolumn{3}{|c|}{134,9} \\
\hline$\sigma_{1}, \mathrm{~kJ} \mathrm{~mol}^{-1}$ & 6,18 & 5,23 & 3,56 \\
\hline $\mathrm{k}_{02}, \mathrm{~s}^{-1}$ & $7,4710^{13}$ & $7,9110^{15}$ & $6,5910^{15}$ \\
\hline $\mathrm{E}_{0,2}, \mathrm{~kJ} \mathrm{~mol}^{-1}$ & \multicolumn{3}{|c|}{205,5} \\
\hline$\sigma_{2}, \mathrm{~kJ} \mathrm{~mol}^{-1}$ & 3,15 & 14,77 & 19,34 \\
\hline $\mathrm{k}_{03}, \mathrm{~s}^{-1}$ & $7,2410^{12}$ & $1,2810^{12}$ & $4,1410^{12}$ \\
\hline $\mathrm{E}_{0,3}, \mathrm{~kJ} \mathrm{~mol}^{-1}$ & \multicolumn{3}{|c|}{209,5} \\
\hline$\sigma_{3}, \mathrm{~kJ} \mathrm{~mol}^{-1}$ & 12,73 & 12,86 & 11,22 \\
\hline $\mathrm{C}_{\mathrm{s} 10}$ & \multicolumn{3}{|c|}{0,215} \\
\hline $\mathrm{C}_{\mathrm{s} 20}$ & \multicolumn{3}{|c|}{0,495} \\
\hline $\mathrm{c}_{\mathrm{s} 30}$ (calculated) & \multicolumn{3}{|c|}{0,289} \\
\hline $\mathrm{k}_{01}$ combustion $/ \mathrm{k}_{01}$ pyrolysis & & 4,5 & 2,9 \\
\hline $\mathrm{k}_{02}$ combustion $/ \mathrm{k}_{02}$ pyrolysis & & 0,0094 & 0,0112 \\
\hline $\mathrm{k}_{03}$ combustion $/ \mathrm{k}_{03}$ pyrolysis & & 5,65 & 1,74 \\
\hline
\end{tabular}

